\title{
Effect of glutaraldehyde fixation and valve constraint conditions on porcine aortic valve leaflet coaptation
}

\author{
NEIL D BROOM, DENIS MARRA
}

From the University Department of Mechanical Engineering, Auckland, New Zealand

ABSTRACT In an investigation of the influence of glutaraldehyde fixation pressure and subsequent valve constraint on the coaptive characteristics of porcine aortic valves, 14 valves were examined, eight having been fixed at low pressure $(\simeq 1 \mathrm{~mm} \mathrm{Hg})$ and six at high pressure $(80 \mathrm{~mm}$ $\mathrm{Hg}$ ). The coaptive ratios of the left and right coronary leaflets in the low-pressure-fixed valves showed a significant improvement over those of the same leaflets in the high-pressure-fixed valves. Inflation to $80 \mathrm{~mm} \mathrm{Hg}$ results in a variable "peeling back" of the coaptive margins of the low-pressure-fixed valves but not of the high-pressure-fixed valves. Comparable coaptive ratios are therefore expected during full inflation of the unconstrained valves fixed both at low pressure and at high pressure. Constraining the low-pressure-fixed valves during inflation to simulate the effect of mounting on a rigid stent produced either a reduction or virtual elimination of this "peeling back" motion or in some instances a slight reversal of the effect, thus increasing the width of the coaptive margin. Hence it is expected that the stented low-pressure-fixed valve will manifest better coaptation than the high-pressure-fixed valve. Finally, the experimental findings of this study, combined with the improved mechanical function of the leaflet tissue already known to occur in the low-pressure-treated valves, provide a convincing case for valve fixation to be carried out under lower pressures.

The glutaraldehyde-treated porcine aortic valve is now extensively used as a bioprosthesis in heart valve replacement surgery. Until recently the significant effect of pressure during glutaraldehyde fixation on the mechanical properties of the treated tissue had not been fully appreciated. Recent studies, however, have shown that the geometric waveform or crimp that is present in the collagenous fibres in the fresh leaflet tissue must be fully retained during fixation if any recoverable extensivity is to be present in the tissue. ${ }^{1}$ This in turn influences the opening behaviour of the leaflets under steady flow conditions. ${ }^{2}$ Further, in vitro rapid-cycle fatigue tests on fixed porcine aortic leaflet specimens have shown that tissue treated at high pressure is more susceptible to mechanical fatigue than is tissue treated at low pressure. ${ }^{3}$

An earlier examination in this laboratory of commercially available glutaraldehyde-treated porcine valves suggested that relatively high pressures had been used during tissue fixation. ${ }^{2}$ While raised pres-

Address for reprint requests: Dr ND Broom, Department of Mechanical Engineering, University of Auckland, Private Bag, Auckland, New Zealand. sures will ensure full closure and sealing of the three leaflets the structural changes that occur with highpressure fixation raise questions about the suitability of this type of valve treatment. Studies carried out in our laboratory suggest that mechanical function in vivo will be improved after low-pressure fixation of the valves provided that adequate sealing of the leaflets can be achieved with low-pressure fixation. The present study is concerned with answering this last question.

\section{Experimental methods}

Tissue fixation Fourteen aortic valves were trimmed from porcine hearts freshly dissected from animals in the live weight range $30-55 \mathrm{~kg}$. The coronary arteries were tied off and then each valve was checked for competence by attaching a length of flexible tubing and applying a hydrostatic pressure. No further preferential selection of valves for subsequent fixation was made either on anatomical grounds or with regard to valve diameter. Fixation was accomplished by filling this tube with $0.625 \%$ glutaraldehyde (in $0.15 \mathrm{~mol} / 1$ phosphate buffer of $\mathrm{pH} 7 \cdot 2$ ). Six valves were fixed at $80 \mathrm{~mm} \mathrm{Hg}$ (hence- 
forth referred to as high-pressure-treated valves). Eight were fixed at less than $1 \mathrm{~mm} \mathrm{Hg}$ (lowpressure-treated valves). The valve diameters measured at their aortic roots varied from 16 to $23 \mathrm{~mm}$. There was shown to be no significant difference between the diameters of the low-pressure and high-pressure series.

Coaptation measurements on unconstrained treated valves On the ventricular surface of each treated valve a series of ink dots was made close to the common line of meeting of each of the coapting leaflets. This procedure was carried out with the valves uninflated. Care was taken to ensure that the valve tissue remained moist throughout. The marked ventricular face of each valve was then photographed, inflated to a pressure of $80 \mathrm{~mm} \mathrm{Hg}$, and then rephotographed to record any movement of the ink dots.

Coaptation measurements with simulated stent constraint The constraining influence of a rigid stent was simulated by mounting the low-pressure-treated valves in cylindrical cases, as shown schematically in figure 1. Plaster of Paris was then poured into the space between the case and the aortic valve. When this was set no part of the aortic wall could expand radially during inflation. The marked ventricular face of each constrained valve was then photographed, inflated to $80 \mathrm{~mm} \mathrm{Hg}$, and rephotographed. This second pair of photographs was then compared with those obtained in the unconstrained condition.

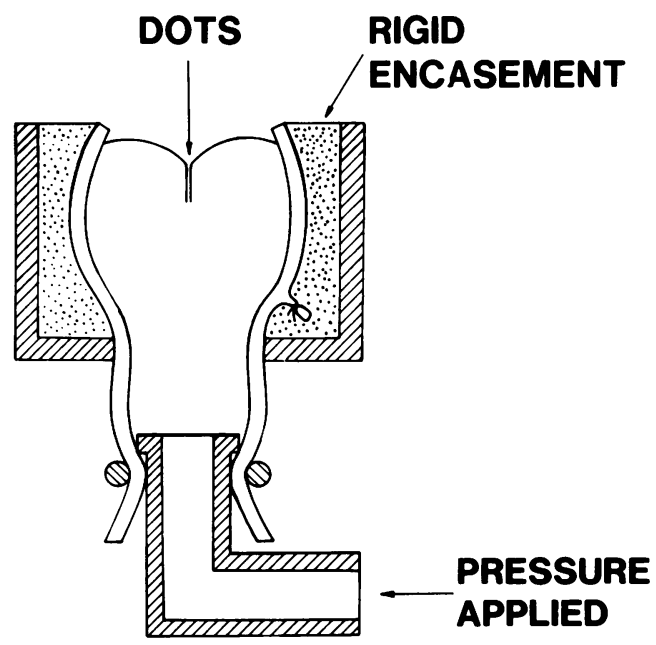

Fig 1 Arrangement used for inflating aortic valves in constrained condition.
Measurement of coaptive areas Each treated valve was then cut along the axis of its aortic wall and laid open to expose the coaptive margins of each leaflet. The leaflets were carefully excised from the aortic wall. By tracing the outline of each leaflet and its appropriate ink markings on to transparent film we could obtain an estimate of the areas of coaptation for each of the leaflets in a given valve. These values are expressed as a percentage ratio of the coaptive area to the total leaflet area. An error of $\pm 6.5 \%$ was estimated in the measurement of this coaptive ratio.

\section{Results}

HIGH-PRESSURE TREATED VALVES

Virtually no change in the coapting margins with inflation was seen in any of the six high-pressuretreated valves. Photographic evidence of this consistent behaviour, from two representative valves, is shown in figure 2 . Table 1 shows the coaptive ratios for the left, right, and non-coronary leaflets from these six valves in their uninflated state. The width of the coapting margins in the leaflets always decreased from a maximum near their attachment to the aortic wall to a minimum at the nodulus of Aranti (see arrows in fig $3 a$ ). In some leaflets this minimum width was reduced to zero (see arrows in fig $3 b$ ), this large difference being attributed to natural anatomical variations.

Table 1 Coaptive ratios (\%) for individual leaflets of high-pressure-fixed valves

\begin{tabular}{llll}
\hline Valve No & Left coronary & Right coronary & Non-coronary \\
\hline HP 1 & 46 & 56 & 51 \\
HP 2 & 45 & 48 & 65 \\
HP 3 & 51 & 50 & 54 \\
HP 4 & 61 & 63 & 70 \\
HP 5 & 48 & 60 & 49 \\
HP 6 & 43 & 40 & 51 \\
Mean and SD & $49 \pm 6.5$ & $53 \pm 8.5$ & $57 \pm 8.7$ \\
\hline
\end{tabular}

Table 2 Coaptive ratios (\%) for individual leaflets of low-pressure-fixed valves

\begin{tabular}{llll}
\hline Valve No & Left coronary & Right coronary & Non-coronary \\
\hline LP 1 & 66 & 61 & 63 \\
LP 2 & 74 & 65 & 64 \\
LP 3 & 56 & 81 & 61 \\
LP 4 & 59 & 56 & 54 \\
LP 5 & 54 & 65 & 66 \\
LP 6 & 50 & 57 & 53 \\
LP 7 & 56 & 64 & 69 \\
LP 8 & 57 & 71 & 71 \\
Mean and SD & $59 \pm 7.5$ & $65 \pm 8.0$ & $63 \pm 6.5$ \\
\hline
\end{tabular}



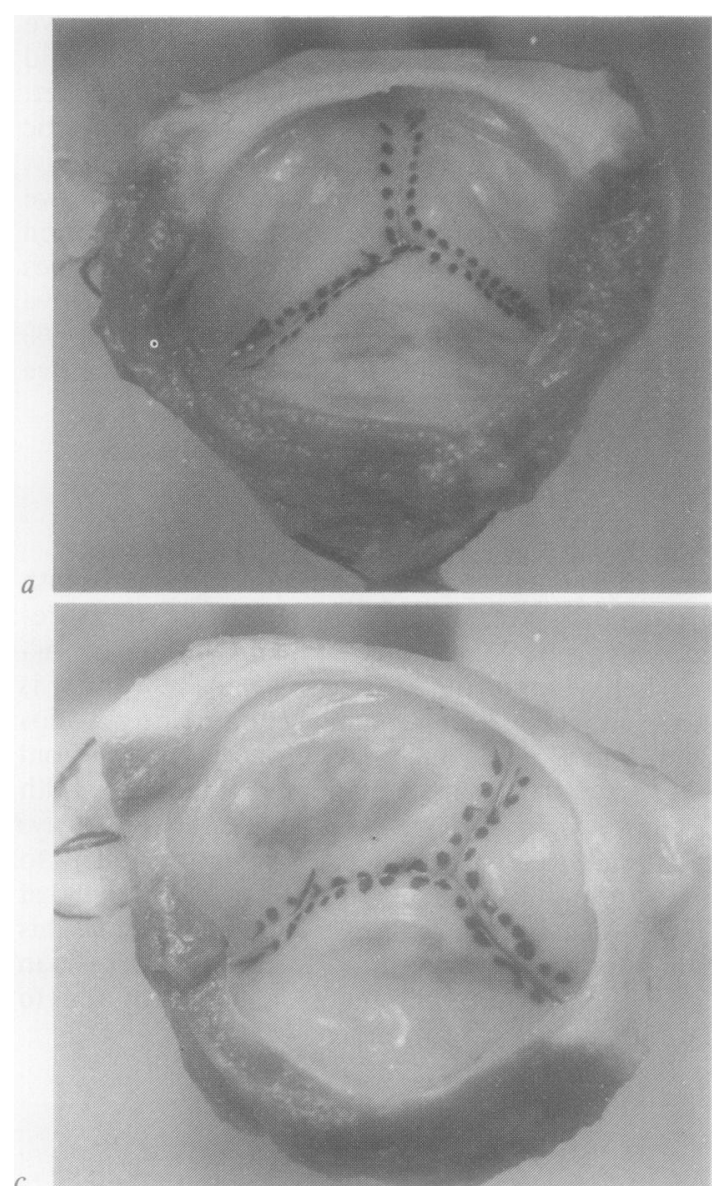
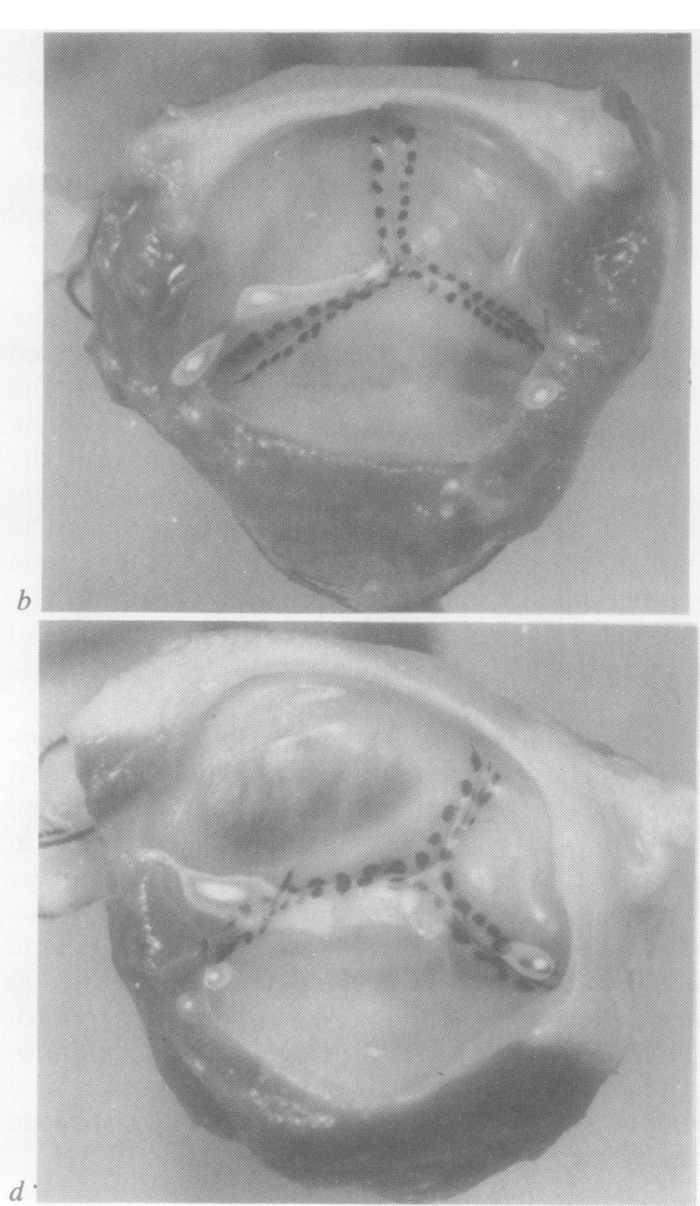

Fig 2 Examples of inflation of high-pressure (HP)-treated valves: (a) valve HP 1, zero pressure; (b) HP 1, inflated $80 \mathrm{~mm}$ $\mathrm{Hg}$; (c) valve HP 2, zero pressure; (d) HP 2, inflated $80 \mathrm{~mm} \mathrm{Hg}$. Note that there is virtually no change in the coaptive margins with inflation.
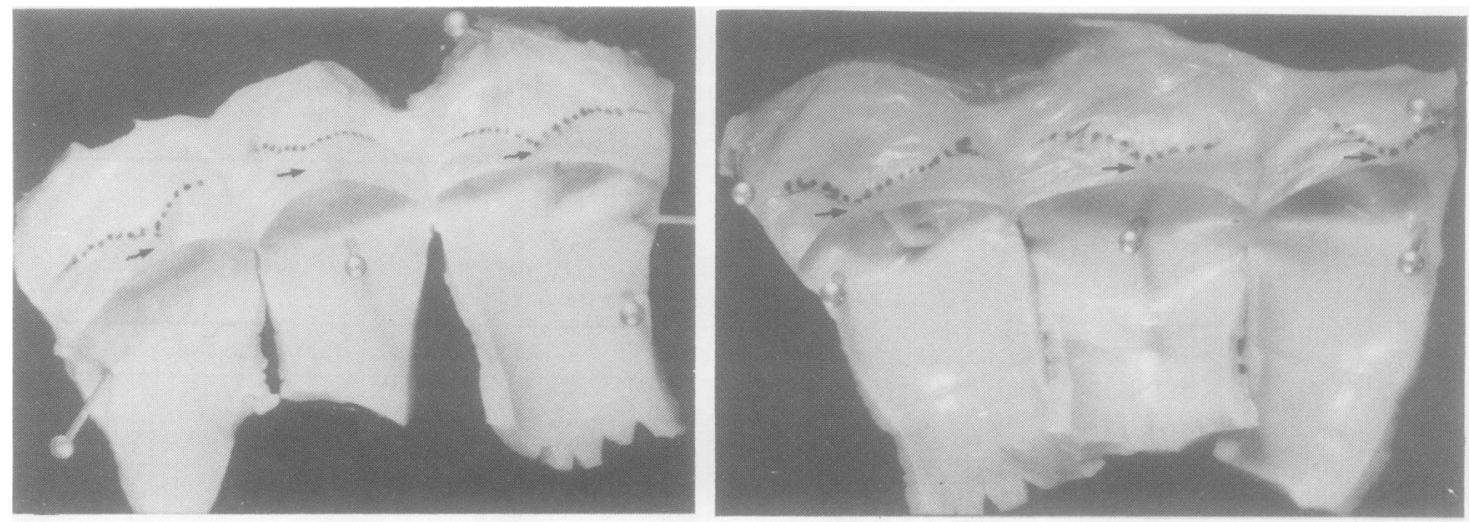

Fig 3 High-pressure-treated valves laid open to indicate shape of coaptive regions of leaflets: (a) HP 1; (b) HP 2. Arrows indicate nodulus of Aranti on each leaflet. 

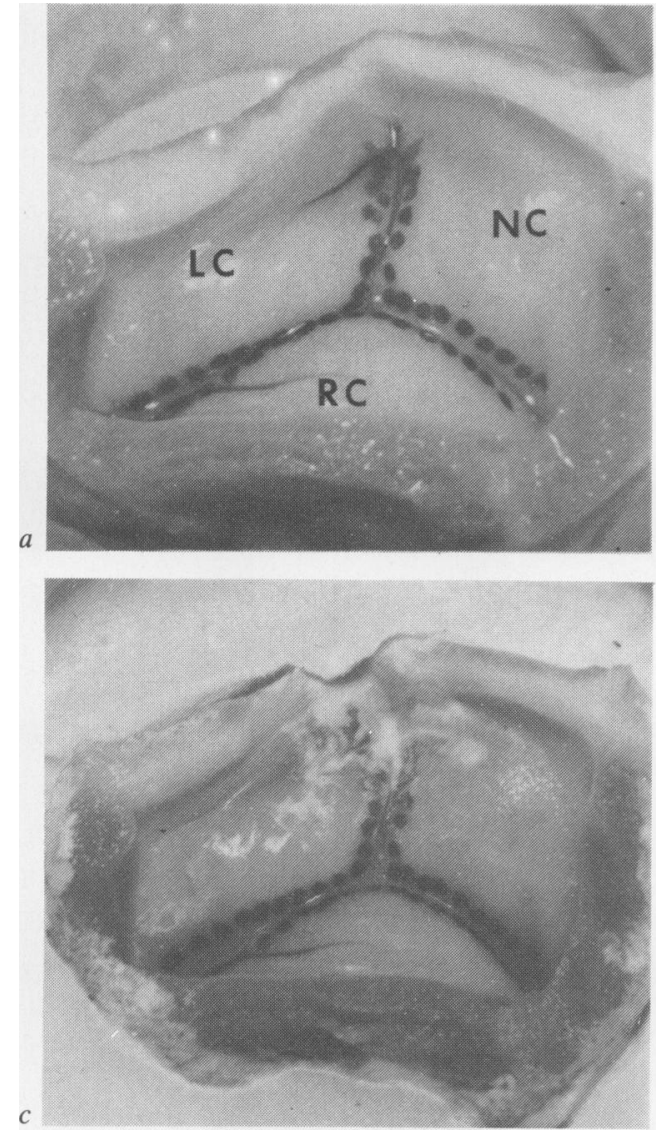
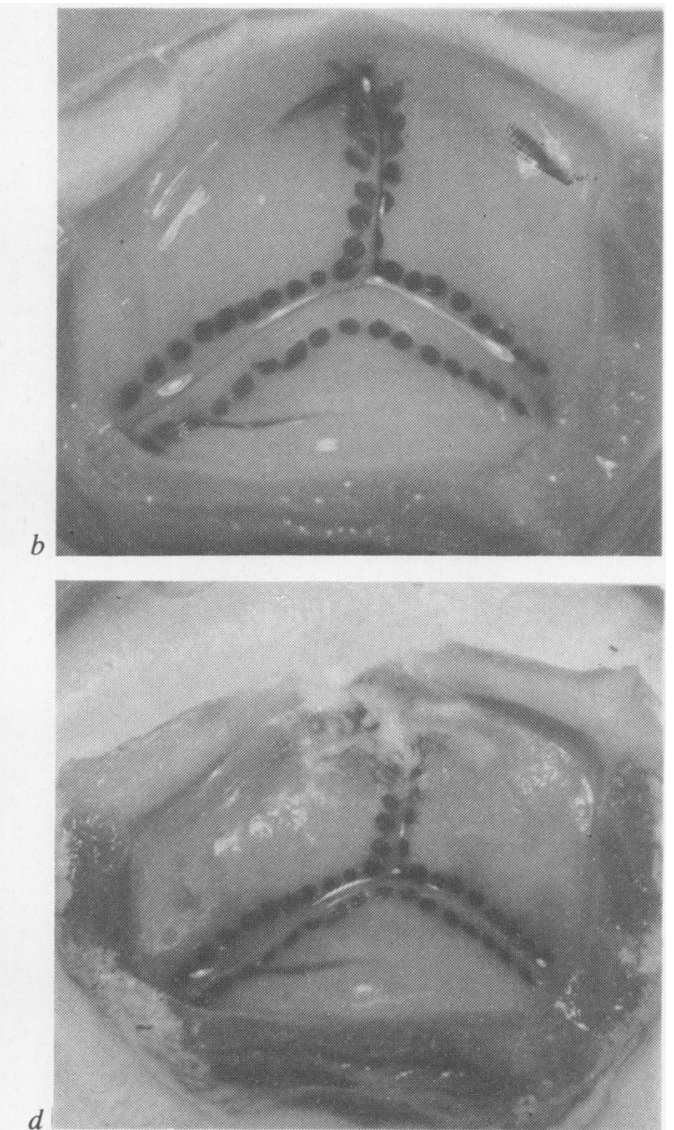

\section{LOW-PRESSURE-TREATED VALVES}

All eight low-pressure-treated valves when inflated to $80 \mathrm{~mm} \mathrm{Hg}$ in their unconstrained state showed an outward movement or "peeling back" of one or more of the dotted lines delineating the coapting margins of adjacent leaflets. For example, in valve LP1 (figs $4 a$ and $4 b$ ) the entire margin of the right coronary leaflet has peeled back significantly, with some movement in that part of the margin of the left coronary leaflet coapting with the right coronary leaflet. In valve LP2 all three leaflets have peeled back (figs $5 a$ and $5 b$ ), whereas in LP3 significant movement has occurred only in the right coronary leaflet (figs $6 a$ and $6 b$ ).

Table 2 records the coaptive ratios for the left, right, and non-coronary leaflets measured in the eight low-pressure-treated valves in their uninflated state. Inflation of all eight low-pressure valves in their fully constrained state produced either a reduction in or elimination of this original leaflet movement (see figs $4 a, 4 b, 4 d$ and $5 a, 5 b, 5 d$ respectively) or a slight reversal of the effect, so increasing the width of the coapting margin (figs $6 a, 6 b, 6 d$ ). As with the high-pressure-treated valves, the width of the coapting margin at the nodulus of Aranti varied considerably from leaflet to leaflet (fig 7).

The Student's $t$ test was applied to the mean values of the coaptive ratios obtained from the valves fixed at high and low pressure. The observed increase in the coaptive ratios of the left and right coronary leaflets of the low-pressure-treated valves over those of the same leaflets in the high-pressuretreated valves was significant to a confidence level greater than $97.5 \%$. Even at the $95 \%$ confidence 

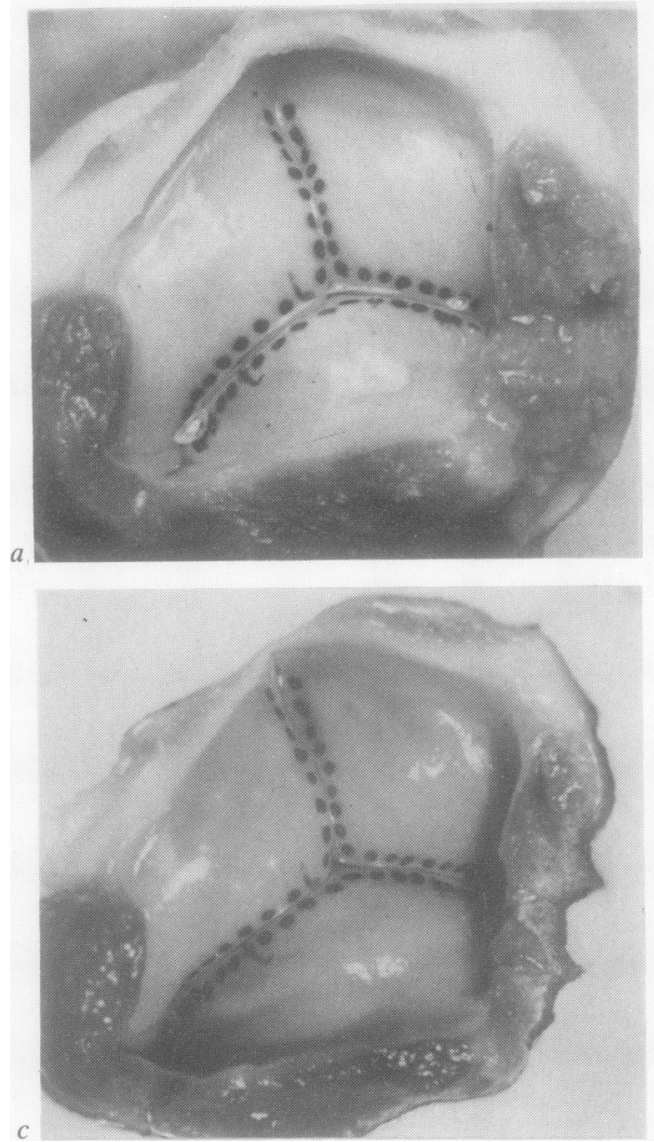
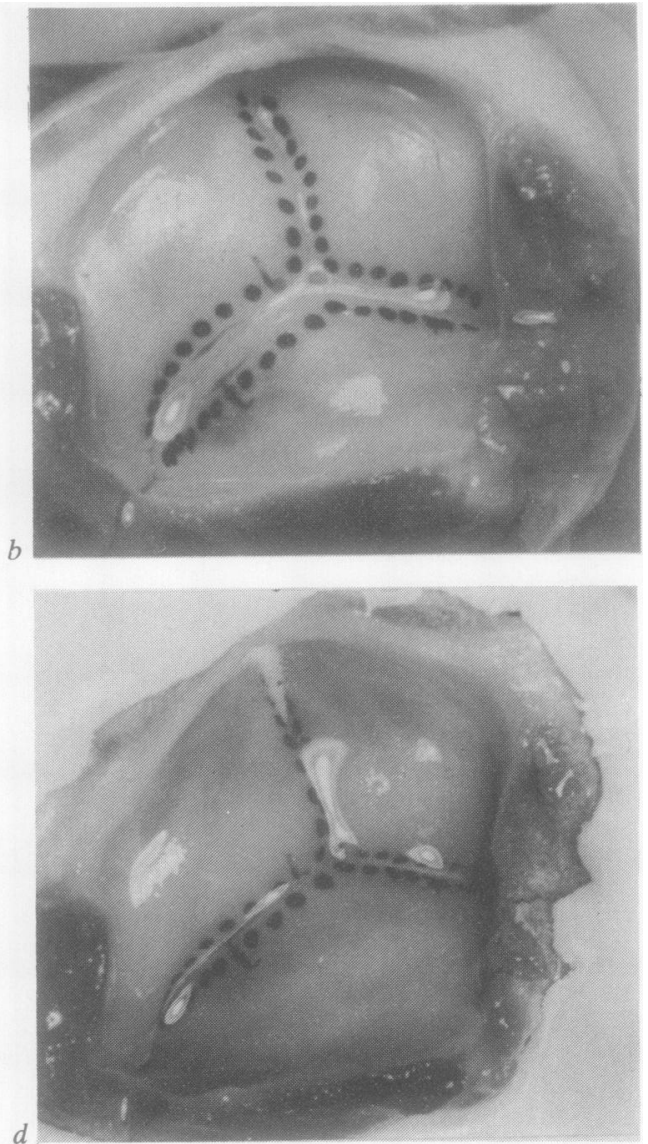

Fig 5 Inflation of low-pressure-treated valve LP 2: (a) unconstrained, zero pressure; (b) unconstrained, inflated $80 \mathrm{~mm}$ $\mathrm{Hg}$; (c) constrained, zero pressure; (d) constrained, inflated $80 \mathrm{~mm} \mathrm{Hg}$.

level, however, no significant difference was found between the means of the non-coronary leaflets from the valves fixed at high and at low pressure.

\section{Discussion}

The results from the high-pressure fixation are consistent with previous studies conducted by one of us. ${ }^{1}$ Inflation of a fresh valve to the physiological pressure of $80 \mathrm{~mm} \mathrm{Hg}$ will expand the collagenous structures to their full extent-that is, straighten their geometric waveform or crimp. Fixation with glutaraldehyde introduces a large number of stable cross-links between the amino acid groups of the polypeptide chains of collagen. ${ }^{45}$ As a result, this fully extended geometry of the collagen in the leaflet is permanently retained and no significant contraction in size occurs in the high-pressure-treated valves with deflation. Thus the coaptation characteristics of these valves should remain more or less unchanged over the range of physiological pressures applied, as is indicated from the results shown in figure 2. Any further constraint imposed on the high-pressure-treated valve should not alter the coaptation characteristics significantly because the valve tissue is virtually inextensible. ${ }^{1}$

With low-pressure fixation a variable is now introduced into the performance of the valve, for within the range of physiological pressure loading a definite distension will occur, particularly in the leaflet tissues. In the unconstrained condition this elasticity results in a reasonably consistent "peeling back" of the coaptive margins, reflecting a reduction in the coaptive area of the leaflets. The amount of reduction for a given valve is difficult to quantify since the separation of the dots will reflect not only a peeling back of the adjacent leaflets from direct contact but also any biaxial stretching occurring within each inflated leaflet.

Previous studies have shown that circumferential 

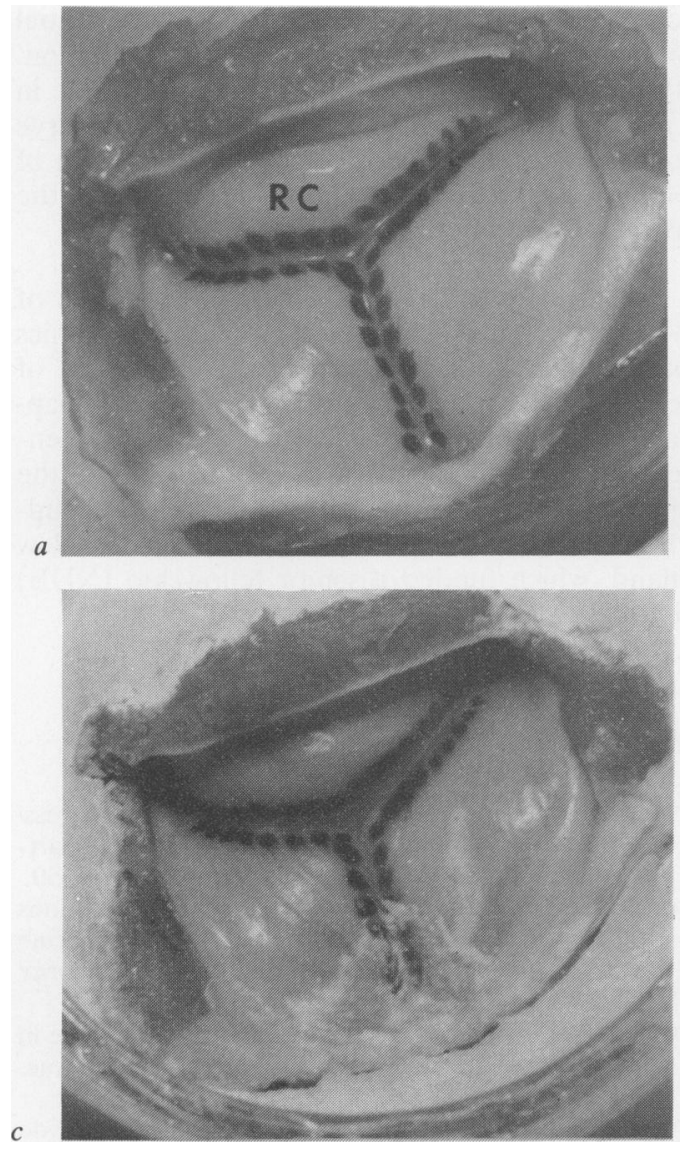
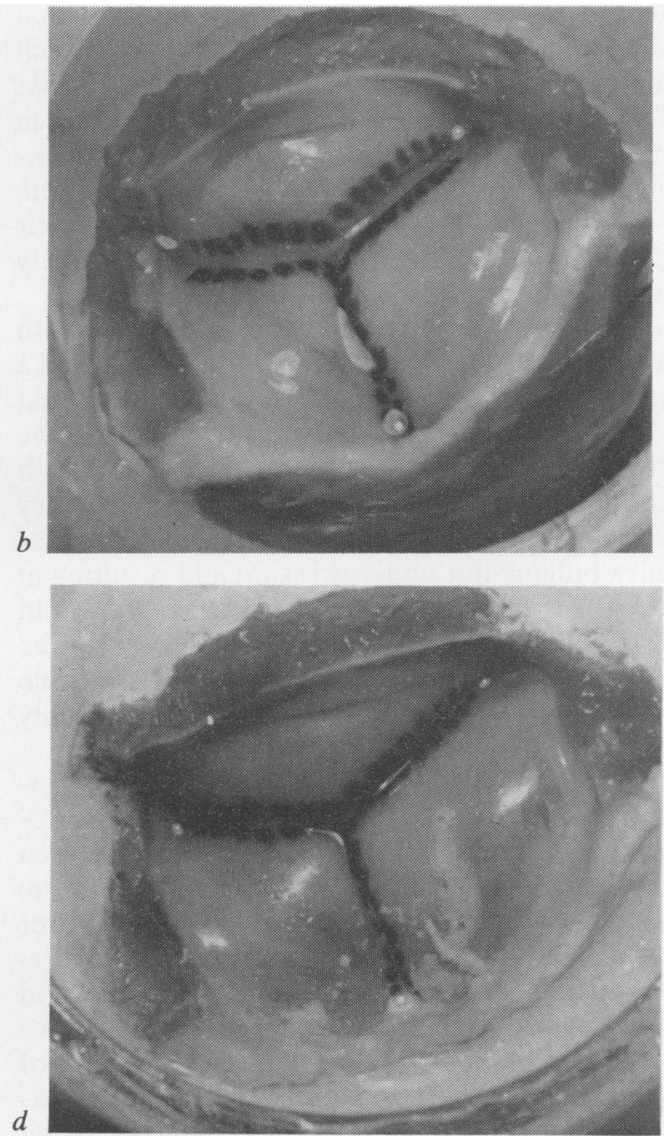

$d$

Fig 6 Inflation of low-pressure-treated valve LP 3: (a) unconstrained, zero pressure; (b) unconstrained, inflated $80 \mathrm{~mm}$ $\mathrm{Hg}$; (c) constrained, zero pressure; (d) constrained, inflated $80 \mathrm{~mm} \mathrm{Hg}$.

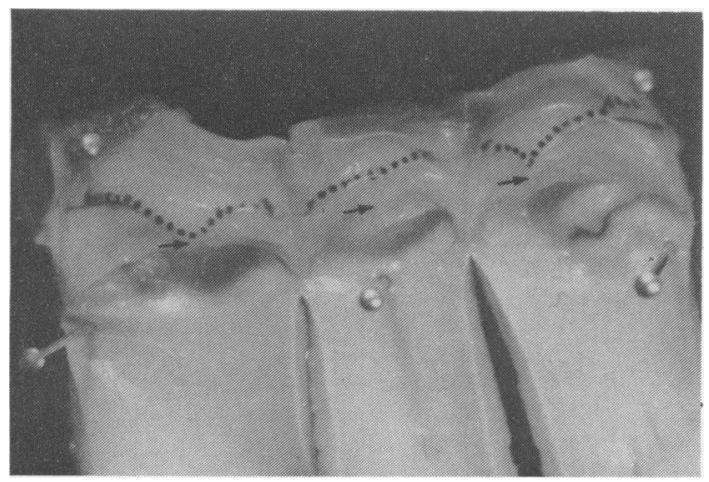

Fig 7 Low-pressure-treated valve LP 5 laid open to indicate shape of coaptive regions of leaflets. Arrows indicate nodulus.of Aranti on each leaflet. strains in the leaflet tissue from valves fixed at low pressure can be as high as $15 \%,{ }^{1}$ and in the radial direction traversing the stiffer circumferential collagen bundles an even greater distension is observed. ${ }^{6}$ Although low-pressure fixation stiffens the valve tissue considerably, inflation to a pressure of $80 \mathrm{~mm} \mathrm{Hg}$ should still distend the unconstrained valve to a condition approaching that reached by the unfixed valve similarly inflated. Justification for this comes from earlier in situ morphological and mechanical studies, which showed that glutaraldehyde fixation largely influences the compliance of the leaflet tissue in the early stages of loading - that is, the incubation portion of the stress-strain curve in which the collagenous waveform or crimp undergoes large geometric changes with only small increases in load. The maximum tissue strain is determined by the straightening of the crimp, and inflation to 80 $\mathrm{mm} \mathrm{Hg}$ is likely to achieve this in the tissue fixed at low pressure. Fixation at $80 \mathrm{~mm} \mathrm{Hg}$ will therefore 
produce a degree of coaptation approaching that shown by the low-pressure-fixed valves at full inflation (compare figs $2 b$ and $2 d$ with figs $4 b, 5 b$, and $6 b$ ). Thus, while there is a significant increase in the mean value of the coaptive ratios of the unconstrained low-pressure-treated valves over that of the high-pressure-treated valves when measured in their uninflated states, this difference will be largely eliminated after inflation to $80 \mathrm{~mm} \mathrm{Hg}$.

These results are qualitatively consistent with those obtained by Swanson and Clark. ${ }^{7}$ They used a technique of rubber cast replication and found that with fresh unconstrained human aortic valves the width of the coapting surfaces decreased with increasing pressure up to $120 \mathrm{~mm} \mathrm{Hg}$. This they showed to be a direct consequence of the sinuses of Valsalva bulging out under pressure and resulting in this peeling back of the coapting surfaces. We would expect to observe a similar trend in behaviour in the low-pressure-treated valve since a true recoverable elasticity is present in the tissue, and this is certainly the case.

The encasement studies show clearly that by constraining all radial movement of the low-pressurefixed valve during inflation this loss of coaptive area is either reduced or eliminated altogether. In some valves the coaptive area actually increased after encasement. Relevant to these experimental observations are the theoretical studies of Christie and Medland. ${ }^{8}$ Using finite element theory they have developed a model for the mechanical behaviour of the aortic heart valve based on anatomical observations of the structure of the leaflet material. Using an isotropic membrane reinforced with circumferential elastic fibres to simulate the leaflet structure, Christie and Medland have examined leaflet behaviour using boundary conditions that simulate the constraining effect of a rigid stent. They found that because the net movement of the leaflet was towards the coapting surface the area of coaptation increased with increasing pressure.

The present experiments do not show a consistent increase in coaptive ratio with increasing pressure as is predicted from the model of Christie and Medland. This is understandable in the light of their theoretical results, which showed that the amount of coaptive change was a function both of the amount of circumferential reinforcement and of the initial positions of adjacent leaflets at the start of inflation. Both these characteristics will be highly variable in the natural valve. Nevertheless, we certainly observe a consistent trend of improvement in coaptation of the low-pressure-fixed valve when it is inflated in the constrained condition.

We are most grateful for the helpful criticisms of GW Christie (theoretical and applied mechanics department, School of Engineering, University of Auckland) and for his statistical analysis of the coaptation measurements. BG Barratt-Boyes (Greenlane Hospital, Auckland) also commented on the original draft of the paper. This research was supported by the Medical Research Council of New Zealand, which funded a senior fellowship (NDB) and a technical post (DLM).

\section{References}

${ }^{1}$ Broom ND. Simultaneous morphological and stress/ strain studies of the fibrous components in wet heartvalve leaflet tissue. Connect Tissue Res 1978;6:37-50.

${ }^{2}$ Broom ND, Thomson FJ. Influence of fixation conditions on the performance of glutaraldehyde-treated porcine aortic valves: towards a more scientific basis. Thorax 1979;34:166-76.

${ }^{3}$ Broom ND. An "in vitro" study of mechanical fatigue in glutaraldehyde-treated porcine aortic valve tissue. Biomaterials 1980;1:3-8.

${ }^{4}$ Rowes $\mathrm{JH}$, Cater $\mathrm{CW}$. The reaction of glutaraldehyde with proteins and other biological materials. $J R$ Microsc Soc 1966;85:193-200.

5 Nimni ME. The molecular organisation of collagen and its role in determining the biophysical properties of the connective tissues. Biorheology 1980;17:51-82.

- Tan AJK. Tensile behaviour of aortic heart valve leaflets and sterilisation effects. ME thesis, School of Engineering, University of Auckland, 1975.

${ }^{7}$ Swanson WM, Clark RE. Dimensions and geometric relationships of the human aortic valve as a function of pressure. Circulation Res 1974;35:871-82.

${ }^{8}$ Christie GW, Medland IC. A non-linear finite element stress analysis of bioprosthetic heart valves. In: Gallagher RH, Simon BR, Johnson PC, Gross JF, eds. Finite elements in biomechanics. London: John Wiley and Sons, 1981. 